\title{
Mechanisms of DNA Sensing on Graphene Oxide
}

\author{
Biwu Liu ${ }^{\S}$ Ziyi Sun ${ }^{\S}$ Xu Zhang and Juewen Liu*
}

Department of Chemistry, Waterloo Institute for Nanotechnology, University of Waterloo, Waterloo,

Ontario, Canada N2L 3G1.

Email: liujw@uwaterloo.ca

This document is the Accepted Manuscript version of a Published Work that appeared in final form in Analytical Chemistry copyright ( $)$ American Chemical Society after peer review and technical editing by publisher. To access the final edited and published work see Liu, B., Sun, Z., Zhang, X., \& Liu, J. (2013). Mechanisms of DNA Sensing on Graphene Oxide. Analytical Chemistry, 85(16), 7987-7993. https:// doi.org/10.1021/ac401845p 


\begin{abstract}
Adsorption of a fluorophore-labeled DNA probe by graphene oxide (GO) produces a sensor that gives fluorescence enhancement in the presence of its complementary DNA (cDNA). While many important analytical applications have been demonstrated, it remains unclear how DNA hybridization takes place in the presence of $\mathrm{GO}$, hindering further rational improvement of sensor design. For the first time, we report a set of experimental evidence to reveal a new mechanism involving non-specific probe displacement followed by hybridization in the solution phase. In addition, we show quantitatively that only a small portion of the added cDNA molecules undergo hybridization while most are adsorbed by GO to play the displacement role. Therefore, it is possible to improve signaling by raising hybridization efficiency. A key innovation herein is using probes and cDNA with a significant difference in their adsorption energy by GO. This study offers important mechanistic insights into the GO/DNA system. At the same time, it provides simple experimental methods to study biomolecular reaction dynamics and mechanism on surface, which may be applied for many other biosensor systems.
\end{abstract}




\section{Introduction}

Graphene and graphene oxide (GO) have emerged as an excellent platform for biomolecular adsorption, mediating chemical reactions, and developing biosensors. ${ }^{1}$ One particularly interesting and important example is the adsorption of single-stranded (ss) DNA. ${ }^{2}$ Even though both are negatively charged, DNA can still be adsorbed by GO in buffers containing a high concentration of salt to screen electrostatic repulsion. The attractive forces between DNA and GO include $\pi-\pi$ stacking, hydrophobic interaction, hydrogen bonding and van der Waals force..$^{3-5}$ Without a covalent linkage, ${ }^{6}$ DNA adsorption is reversible. For example, adsorbed DNA can be desorbed by adding its complementary DNA (cDNA) to form a duplex. Compared to ss-DNA, the affinity between a double-stranded (ds) DNA and GO is much weaker. ${ }^{7}$ Since GO is also a fluorescence quencher, fluorophore-labeled DNA and aptamers have been extensively coupled with GO as an analytical tool for detecting nucleic acids, ${ }^{2,8}$ metal ions, ${ }^{9}$ small molecules,${ }^{10-13}$ proteins, ${ }^{14}$ and cells. ${ }^{15}$ The GO/DNA sensors have gained extensive interests due to simplicity in design, high signal-to-background ratio, and great sensitivity, which are critical for developing turn-on fluorescent sensors. ${ }^{2}$ Despite these practical applications, it remains unclear how such analyte-induced desorption reaction takes place at the molecular level. A critical question is whether DNA hybridization can directly occur on the GO surface or in the solution phase. Most previous physical studies only measured adsorption energy with little dynamic information available, thus inadequate to reveal a clear physiochemical picture of the DNA sensing mechanism. ${ }^{16-18}$

If we borrow terms from surface-catalyzed gas phase reactions, DNA hybridization in the presence of GO can be described by a few possible mechanisms. We herein consider a GO surface preadsorbed with a fluorophore-labeled probe DNA, producing a dark background because of fluorescence quenching by GO. After adding the cDNA (e.g., the target DNA), fluorescence enhancement is observed. If this reaction follows the Langmuir-Hinshelwood mechanism, the cDNA is also adsorbed followed by diffusion on GO. When the cDNA meets a probe DNA, a duplex is formed on the GO surface and then desorbed (Figure 1A). This is a common mechanism for surface-catalyzed gas phase 
reactions since both reactants might be activated by the surface to lower the activation energy barrier. Another possibility is the Eley-Rideal mechanism, where the adsorbed probe DNA directly reacts with its cDNA that is dissolved in the solution phase (e.g. the cDNA does not have to be adsorbed, Figure 1B) at the GO/water interface. The exact mechanism has not been established with experimental evidence, but most previous work assumed one of the abovementioned mechanisms. ${ }^{2}$ In other words, the general perception on this issue is that at least one DNA is adsorbed by GO during the hybridization reaction.

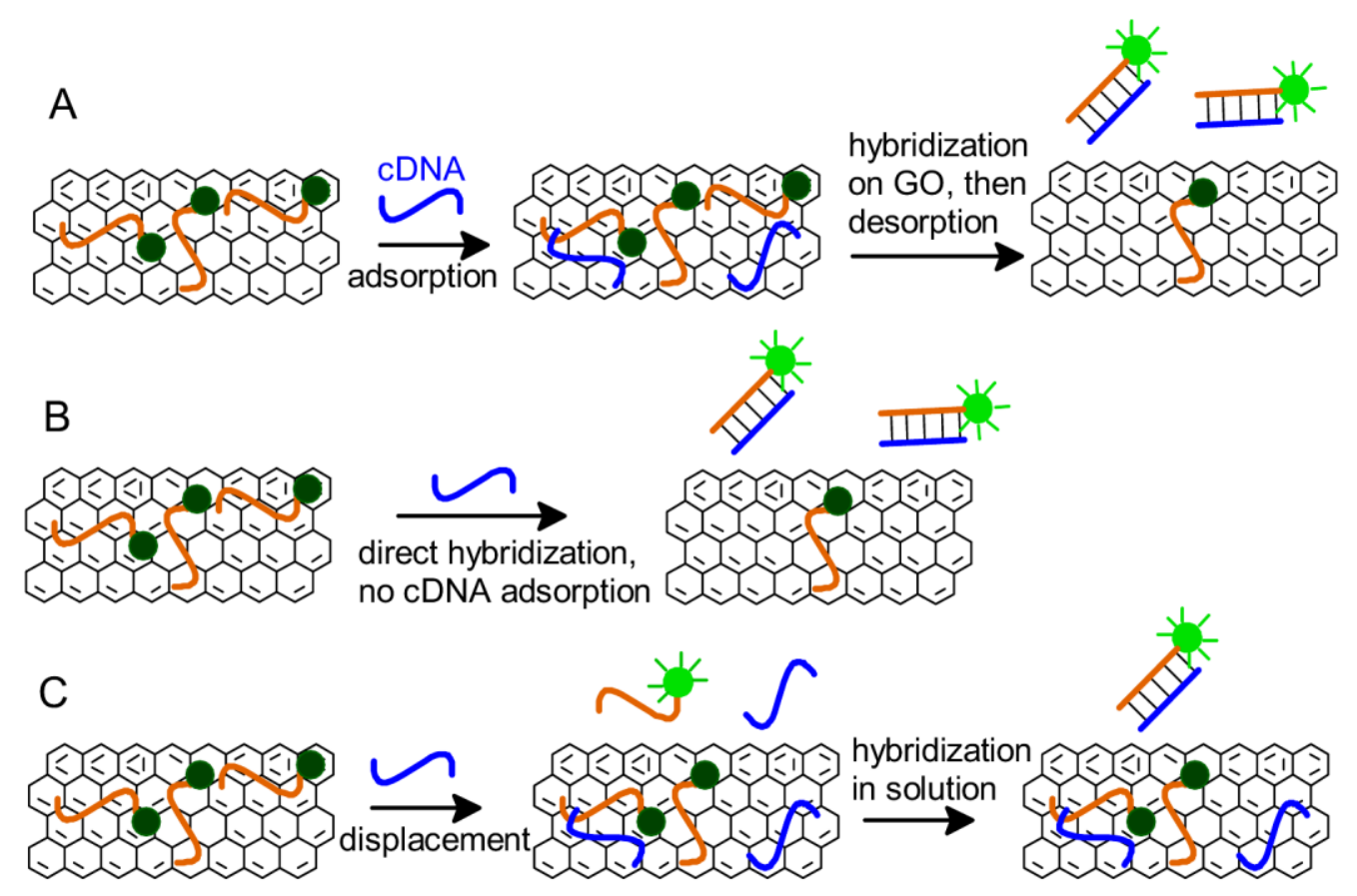

Figure 1. Three possible mechanisms of hybridization between a probe DNA adsorbed by GO and its cDNA (target DNA). The oxygenated groups and defeats on GO are not drawn for clarity of the figures. In all the cases, the probe DNA with a fluorophore label is pre-adsorbed and the cDNA is added afterwards. The tendency of GO adsorbing ds-DNA is lower than the adsorption of ss-DNA. (A) The Langmuir-Hinshelwood mechanism. (B) The Eley-Rideal mechanism. (C) The displacement mechanism. 
There are still other possibilities that can also explain the fluorescence enhancement. For example, the added cDNA might compete with the adsorbed probe DNA non-specifically for surface binding sites. Some of the probe DNA might be displaced by the cDNA into the solution phase to hybridize with the free cDNA (Figure 1C). So far, it has been quite challenging to conclude on a molecular scale mechanism, leading to difficulties towards rational improvement of biosensor design. In addition, considering the extensive research interests on graphene-based materials, understanding its role in biomolecular reactions is crucial for many other applications including device fabrication, targeted drug delivery and imaging. We herein report a set of experiments to provide key insights into this important analytical system.

\section{Materials and Methods}

Chemicals. The dual-labeled DNA samples were from Gene Link Inc (Hawthorne, NY) and all the other DNAs were from Integrated DNA Technologies (Coralville, IA). See Table 1 for DNA sequences. The GO sample was purchased from Advanced Chemical Supplier (ACS) Material (Medford, MA). See Figure S1 for a TEM micrograph. The salts and buffers were from Mandel Scientific (Guelph, ON, Canada).

DNA melting curves. FAM-labeled DNA $(2 \mu \mathrm{M})$ was incubated with $\mathrm{GO}(200 \mu \mathrm{g} / \mathrm{mL})$ in $10 \mathrm{mM}$ $\mathrm{MgCl}_{2}$ for $1 \mathrm{hr}$ followed by three centrifugation (15,000 rpm, $\left.20 \mathrm{~min}\right)$ and washing steps using buffer $\mathrm{A}$ (50 mM HEPES, pH 7.6 and $50 \mathrm{mM} \mathrm{NaCl)}$. Finally the complex was dispersed in buffer A with $\sim 50$ $\mu \mathrm{g} / \mathrm{mL}$ of $\mathrm{GO}$ in a PCR tube. Its fluorescence was monitored as a function of temperature in a real-time PCR thermocycler (CFX-96, Bio-Rad). To measure duplex DNA melting, non-labeled $\mathrm{A}_{15}$ and $\mathrm{T}_{15}$ was mixed at $1 \mu \mathrm{M}$ and annealed in buffer A. A final of $5 \mu \mathrm{M}$ SYTO-13 dye was added to monitor DNA melting using the thermocycler. 
DNA adsorption/desorption. The DNA/GO complex was prepared by mixing AF- $\mathrm{A}_{15}$ or AF-T 15 DNA with $\mathrm{GO}$ in $2 \mathrm{mM} \mathrm{MgCl}, 10 \mathrm{mM}$ HEPES, $\mathrm{pH}$ 7.6. The final concentration of $\mathrm{GO}$ was $50 \mu \mathrm{g} / \mathrm{mL}$ and DNA was $1 \mu \mathrm{M}$. The mixtures were incubated overnight, centrifuged to remove free DNA in the supernatant and washed with buffer (10 mM HEPES, pH 7.6, $100 \mathrm{mM} \mathrm{NaCl}$ ). Desorption experiment was carried out with the fluorescence plate reader with two channels (Infinite F200 Pro, Tecan). Each well contained $90 \mu \mathrm{L}$ of buffer (10 mM HEPES, pH 7.6, $2 \mathrm{mM} \mathrm{MgCl}_{2}$ ). FAM-labeled $\mathrm{A}_{15}$ and $\mathrm{T}_{15}$ (final concentration $=200 \mathrm{nM}$ ) were then added to induce desorption reaction. Similar procedures were used for desorption of FAM-labeled DNA using non-labeled DNAs.

Dual labeled probes. Similar procedures were used to study desorption of dual-labeled probes (in Figure 4) from GO, where the adsorbed probe was $5 \mathrm{nM}$ and cDNA was $200 \mathrm{nM}$. For the hybridization reaction in solution, $5 \mathrm{nM}$ probe DNA and $200 \mathrm{nM}$ cDNA was mixed in buffer (5 mM HEPES, pH 7.6 with $5 \mathrm{mM} \mathrm{MgCl} 2$ and $100 \mathrm{mM} \mathrm{NaCl}$ ). A lower probe concentration was used here since we intend to compare with solution phase hybridization without GO.

Table 1. DNA sequences used in this work.

\begin{tabular}{|l|l|l|}
\hline DNA name & Sequences and modifications $\mathbf{( 5}^{\prime}$ to $\left.\mathbf{3}^{\prime}\right)$ & in the paper \\
\hline FAM-A 15 & FAM-AAAAAAAAAAAAAAA & Figure 2,3 \\
\hline FAM- $_{15}$ & FAM-TTTTTTTTTTTTTTT & Figure 2,3 \\
\hline $\mathrm{A}_{15}$ & AAAAAAAAAAAAAAA & Figure 2 \\
\hline $\mathrm{T}_{15}$ & TTTTTTTTTTTTTTT & Figure 2 \\
\hline AF-A $_{15}$ & Alexa Fluor 647-AAAAAAAAAAAAAAA & Figure 3 \\
\hline AF-T 15 & Alexa Fluor 647- TTTTTTTTTTTTTTT & Figure 3 \\
\hline Non-structured probe & FAM-TTCTTTCTTCCCCTTGTTTGTT-TAMRA & Figure 4C \\
\hline cDNA for non-structured probe & AACAAACAAGGGGAAGAAAGAA & Figure 4C \\
\hline Hairpin probe & FAM-GCGAGCCAGGTTCTCTTCACAGA & Figure 4D \\
& TGCGCTCGC-Black Hole Quencher1 & \\
\hline cDNA for hairpin probe & ACGCATCTGTGAAGAGAACCTGGG & Figure 4D \\
\hline
\end{tabular}




\section{Results and Discussion}

In most previous studies, DNA probes with mixed nucleotide contents were employed for DNA detection. With such sequences, it is likely that both the probe DNA and its cDNA have similar adsorption affinities to the GO surface, thus blurring the hybridization mechanism. We reason that useful insights might be obtained by using DNA homo-polymers, which may maximize the difference in the adsorption energy of DNA probe towards the GO surface in relative to its cDNA. Based on previous studies, ${ }^{4,19}$ the purine bases (e.g. A and G) bind to graphene more strongly than the pyrimidines (e.g. $\mathrm{T}$ and $\mathrm{C}$ ). In this study, we chose to test $\mathrm{A}_{15} / \mathrm{T}_{15}$ (e.g. 15-mer DNA composed of just A or $\mathrm{T}$ bases) rather than $\mathrm{G}_{15} / \mathrm{C}_{15}$, since poly- $\mathrm{G} / \mathrm{C}$ can form various secondary structures that may complicate our analysis.

To confirm the order of DNA adsorption affinity, we measured the thermal desorption of 5'FAM (carboxyfluorescein)-labeled DNA from GO. The DNA/GO conjugates were exposed to increasing temperatures and the fluorescence intensity at each temperature was measured, which indicates the amount of desorbed DNA. FAM-A 15 did not show much desorption, as indicated by the lack of fluorescence increase (Figure 2A, black curve), while FAM-T 15 showed significant fluorescence enhancement and thus desorption (red curve), confirming its weaker affinity. The melting temperature ( $T_{\mathrm{m}}$, e.g. the maximum of the first derivative) of $\mathrm{T}_{15}$ is determined to be $60{ }^{\circ} \mathrm{C}$ (inset of Figure $2 \mathrm{~A}$ ). For comparison, we also measured the melting curve of a DNA duplex composed of $\mathrm{T}_{15} / \mathrm{A}_{15}$ in the absence of GO (Figure 2B), where the $T_{\mathrm{m}}$ was $\sim 44{ }^{\circ} \mathrm{C}$. These experiments indicate that the stability of the $\mathrm{T}_{15} / \mathrm{A}_{15}$ duplex is slightly lower than the $\mathrm{T}_{15} / \mathrm{GO}$ complex, while $\mathrm{A}_{15} / \mathrm{GO}$ is the most stable since it fails to dissociate by heating.

It needs to be noted that the surface of GO is highly heterogeneous, containing both highly oxidized domains as well as crystalline carbon domains. ${ }^{20,21}$ DNA adsorbed on the carbon domains is more stable than on the oxidized domains. This explains the broad desorption profile of FAM- $\mathrm{T}_{15} / \mathrm{GO}$ 
in Figure 2A. These melting curves were measured in a low salt buffer containing just $50 \mathrm{mM} \mathrm{NaCl}$. With a high salt concentration (e.g. $5 \mathrm{mM} \mathrm{Mg}^{2+}$ ), even FAM-T 15 failed to desorb (Figure S2).

After confirming the order of DNA adsorption energy, we next studied DNA-induced desorption. When FAM-T 15 was used as the pre-adsorbed probe, adding $\mathrm{A}_{15}$ resulted in a large fluorescence increase (Figure $2 \mathrm{C}$, green curve). This is attributed to the formation of the FAM-T $15 / \mathrm{A}_{15}$ duplex. If a non-labeled $\mathrm{T}_{15}$ was added, slow and moderate fluorescence increase was observed due to non-specific displacement of the adsorbed FAM- $\mathrm{T}_{15}$ (blue curve) by $\mathrm{T}_{15}$. Without any added DNA, the adsorbed probe DNA was quite stable and the background fluorescence did not change (red curve). This is the typical scenario reported in most DNA detection papers.

Next, we employed FAM-A 15 as the pre-adsorbed probe. Surprisingly, when $\mathrm{T}_{15}$ was added, the fluorescence increase was very slow (Figure 2D, green curve), even slower than the displacement reaction induced by adding $\mathrm{A}_{15}$ (blue curve). This result allows us to rule out the Eley-Rideal mechanism (Figure 1B). If hybridization were taking place on the GO/water interface when FAM-A 15 was pre-adsorbed, one would expect more efficient fluorescence enhancement by adding $\mathrm{T}_{15}$ than adding $\mathrm{A}_{15}$, because $\mathrm{A}_{15}$ cannot hybridize with FAM- $\mathrm{A}_{15}$. Since we observed the opposite, reactions other than hybridization might be the rate-limiting step.

The difference in cDNA induced desorption between FAM-A 15 and FAM-T 15 does not support the Langmuir-Hinshelwood mechanism either (Figure 1A), which contains four steps: adsorption of both DNA by GO, DNA diffusion on surface, cDNA/DNA hybridization on GO, and release of the resulting duplex into solution to generate fluorescence. If both DNAs must be adsorbed by GO before hybridization, we expect a similar kinetics regardless whether FAM-A 15 or FAM-T 15 is used as the preadsorbed probe as long as the adsorption kinetics of $\mathrm{A}_{15}$ or $\mathrm{T}_{15}$ is comparable. To confirm the adsorption kinetics, we respectively monitored the adsorption of FAM-A 15 and FAM-T F $_{15}$ (Figure S3). Adsorption was finished in $\sim 20 \mathrm{sec}$ for both DNA, much faster than the desorption kinetics. Therefore, the difference in Figure 2C and 2D must be due to reactions after the DNA adsorption step. In fact, 
both mechanisms can be ruled out based on the adsorption energy argument; under our experimental conditions, the DNAs are more stable when they are single-stranded and adsorbed to GO than forming a duplex (Figure 2A, B).
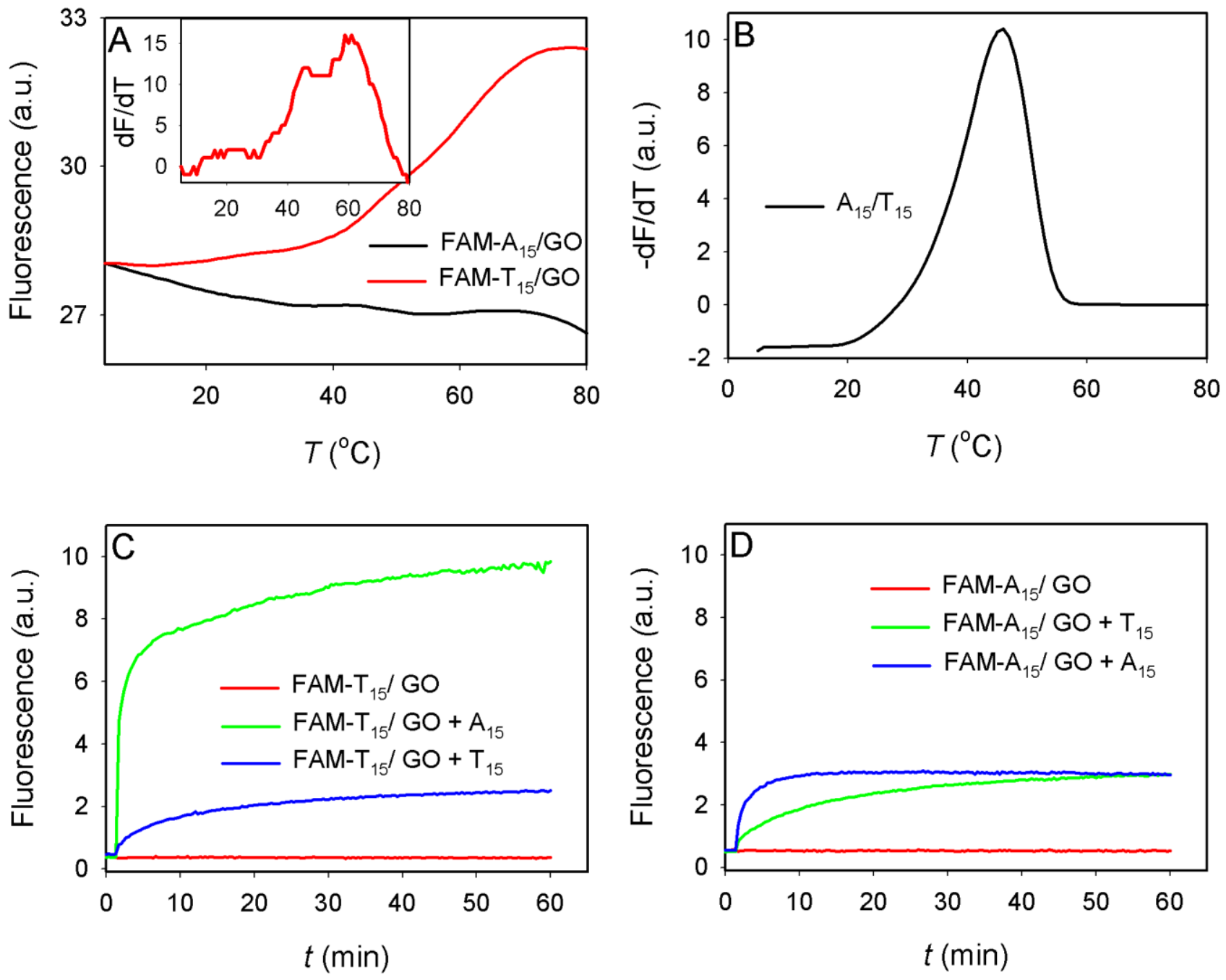

Figure 2. (A) Thermal desorption of FAM- $\mathrm{A}_{15}$ and $\mathrm{FAM}-\mathrm{T}_{15}$ from $\mathrm{GO}$ in buffer (50 mM HEPES, $\mathrm{pH}$ 7.6, $50 \mathrm{mM} \mathrm{NaCl}$ ). Inset: the first derivative of the FAM- $\mathrm{T}_{15}$ desorption profile. (B) $\mathrm{A}_{15} / \mathrm{T}_{15}$ melting trace (first derivative) in the same buffer. Kinetics of fluorescence enhancement upon adding various DNA to FAM-T ${ }_{15} / \mathrm{GO}(\mathrm{C})$ or to FAM-A ${ }_{15} / \mathrm{GO}(\mathrm{D})$. The DNAs were added at $1 \mathrm{~min}$. 
Figure 2D directly points to the importance of non-specific displacement. Since the mechanisms related to direct DNA hybridization on GO have already been ruled out, we reason that the key step is the displacement of the adsorbed probe DNA by its cDNA. DNA cannot directly hybridize on GO since it is energetically unfavorable to do so. On the other hand, the displacement reaction requires little to no net energy (e.g. in the case of $\mathrm{A}_{15}$ displacing FAM-A 15 ) and is driven by the mass action law. In addition, displacement requires lower activation energy than desorption/hybridization since biopolymer displacement on surfaces can often take a concerted mechanism. ${ }^{22,23}$ After being displaced, the desorbed probe reacts with the cDNA in solution to form a duplex as schematically shown in Figure 1C. Fluorescence enhancement was due to the unfavorable re-adsorption of the ds-DNA.

Based on the above discussion, the added cDNA or target DNA has two roles. 1) The adsorbed cDNA displaces the probe DNA into solution; and 2) the cDNA in solution hybridizes with desorbed probes to prevent its re-adsorption. Therefore, we can deduce that the target DNA is not utilized efficiently since ideally each target DNA should generate one hybridization event or one desorbed fluorophore. To track the partition of cDNA, we employed cDNA labeled with a different fluorophore (Figure 3A). To minimize fluorescence resonance energy transfer (FRET) in the duplex formed between these two DNAs, we chose to use FAM and Alexa Fluor 647 (AF) as labels since they form a poor FRET pair. When AF-A 15 was pre-adsorbed as the probe, adding $200 \mathrm{nM}$ FAM-T 15 resulted in just $\sim 5 \%$ or $\sim 3 \mathrm{nM}$ AF- $\mathrm{A}_{15}$ desorption (Figure 3B, green line). At the same time, $\sim 40 \mathrm{nM}$ FAM-T 15 was adsorbed (Figure 3C, green curve). If $200 \mathrm{nM}$ FAM-A $\mathrm{A}_{15}$ was added, $\sim 8 \mathrm{nM}$ AF-A 15 was desorbed (Figure 3B, red curve) and $60 \mathrm{nM}$ FAM-A 15 was adsorbed (Figure 3C, red curve). In both cases, the efficiency of signal generation was quite low. With $200 \mathrm{nM}$ added DNA, only $1.5-4 \%$ equivalent of the probe DNA desorbed. We also compared AF-T $\mathrm{T}_{15}$ desorption induced by FAM-A 15 and non-labeled $\mathrm{A}_{15}$, where the kinetics were quite similar and these labels do not affect the reaction kinetics (Figure S4). However, we cannot rule out that other fluorophores, especially cationic and hydrophobic ones, might induce a different behavior from non-labeled DNA. 

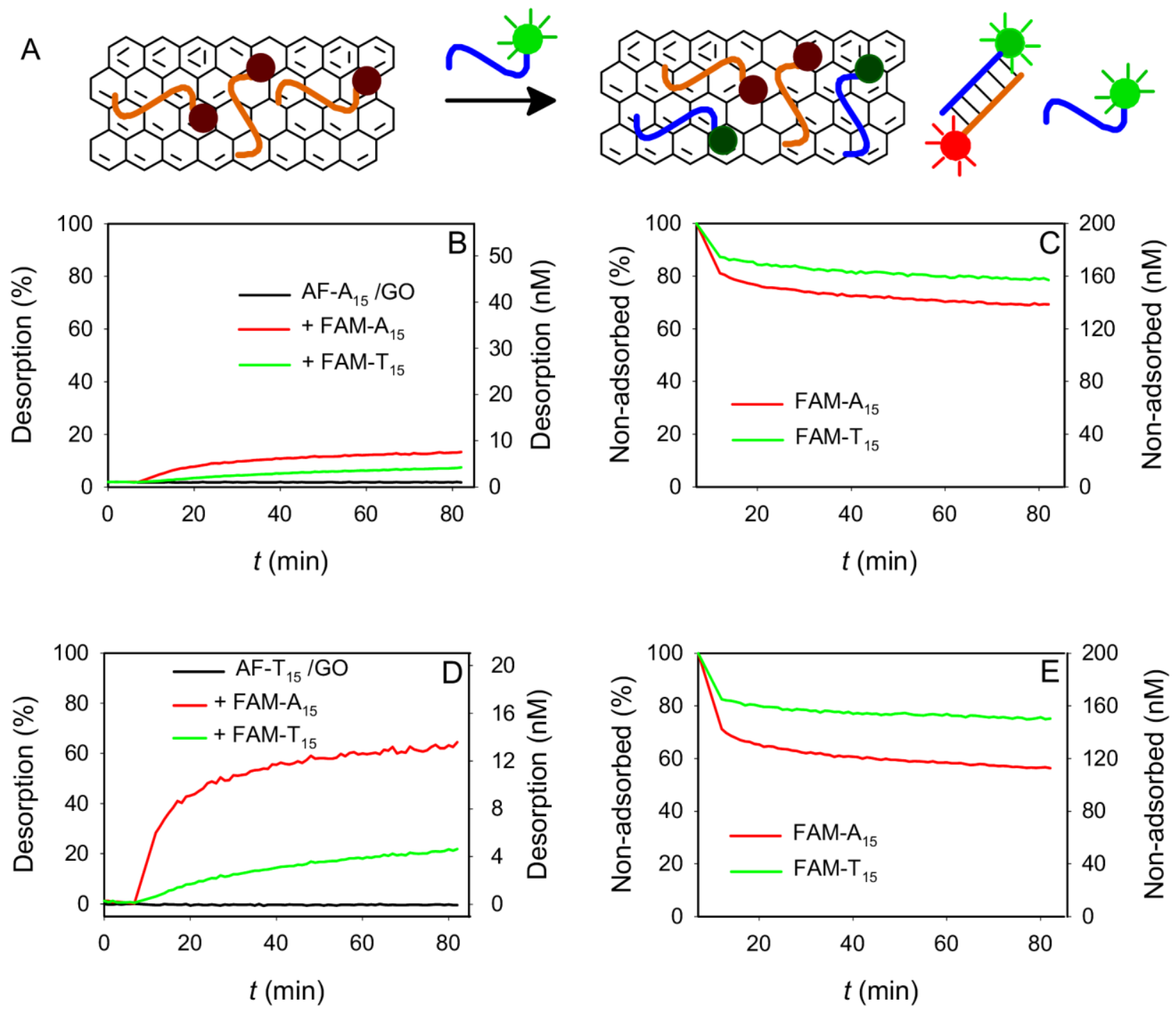

Figure 3. (A) A scheme of quantifying DNA adsorption and desorption using a dual fluorophore approach. Desorption of AF-A 15 (B) or AF-T 15 (D) by FAM-labeled DNA. Adsorption of FAM-labeled DNA in the presence of pre-adsorbed $\mathrm{AF}_{-} \mathrm{A}_{15}(\mathrm{C})$ or $\mathrm{AF}^{-} \mathrm{T}_{15}$ probes $(\mathrm{E})$. The plots were made to compare both the percentage (the left axis) and absolute concentration (the right axis) of DNA adsorption/desorption. 
When AF-T 15 was pre-adsorbed as the probe, adding 200 nM FAM-A 15 resulted in $\sim 60 \%$ or 14 $\mathrm{nM}$ probe desorption (Figure $3 \mathrm{D}$, red line). At the same time, $\sim 80 \mathrm{nM}$ FAM-A 15 was adsorbed. This is a better signaling condition compared to that in Figure $3 \mathrm{~B}$ and is analyzed in more detail. We can divide the added $200 \mathrm{nM}$ FAM-A $\mathrm{A}_{15}$ DNA into three populations. The majority remains in the solution phase as ss-DNA $(\sim 106 \mathrm{nM})$ since the surface has limited capacity. A fraction is in the ds-DNA form $(\sim 14 \mathrm{nM})$ paired with desorbed $\mathrm{AF}-\mathrm{T}_{15}$, assuming that the $\mathrm{AF}_{-\mathrm{T}_{15}} / \mathrm{FAM}-\mathrm{A}_{15}$ duplex is not re-adsorbed by GO. Although ds-DNA can also be adsorbed, ${ }^{7}$ this is a reasonable assumption here since the surface is already saturated with ss-DNA. The remaining FAM-A $15(\sim 80 \mathrm{nM})$ is adsorbed by the GO surface to displace $\mathrm{AF}_{15}$. In the ideal case, all the $200 \mathrm{nM}$ FAM-A 15 should be used to generate signal by forming duplex. However, only $14 \mathrm{nM}$ achieved it. In this experiment, we used an excess amount of the FAM-A 15 to push more probe DNA off the GO surface. If we just consider DNA adsorbed by GO and those formed ds-DNA, $\sim 14 / 94=15 \%$ of the cDNA resulted in the AF- $\mathrm{T}_{15}$ probe desorption. In a simple model, to desorb one equivalent of probe DNA, at least six to seven equivalents of its cDNA need to be added (sequence dependent). This calculation also supports the displacement mechanism; it takes six equivalent of cDNA to displace one equivalent adsorbed DNA. Despite its low efficiency, such GObased sensors can still achieve high sensitivity and often detect down to $1 \mathrm{nM}$ DNA. This is attributed to the extremely low background fluorescence and small background fluctuation. After understanding the reaction mechanism, future work can be geared towards rational improvement of sensor signaling such as blocking the GO surface after probe adsorption and tuning probe adsorption energy. We also tested the reaction at lower probe density and similar results were observed (Figure S5). Therefore, the displacement mechanism is a general conclusion for this DNA/GO system.

A reaction can take many different routes (e.g. Figure 1) and the one with the lowest activation energy and the fastest rate wins. If DNA hybridization follows the Langmuir-Hinshelwood mechanism, a hidden assumption is that hybridization should be faster on GO (e.g. GO serves as a hybridization catalyst). To study the role of GO, we compared the DNA hybridization rate in the presence and 
absence of GO. First, a non-structured DNA probe with terminal fluorophore and quencher labels was employed (Figure 4A). In the absence of GO, hybridization with its cDNA was very fast; signal was saturated in less than 20 seconds (Figure 4C, red trace). The amount of fluorescence enhancement was low since the initial distance between the fluorophore and quencher might be quite long already; forming ds-DNA with its cDNA only caused slightly more separation between the fluorophore and quencher. On the other hand, if we first adsorbed the probe DNA by GO, a much slower kinetics was observed, indicating that GO is not a catalyst but rather an inhibitor for DNA hybridization in general. This is understandable since DNA binds to GO strongly and this strong interaction has to be disrupted to allow for DNA hybridization.
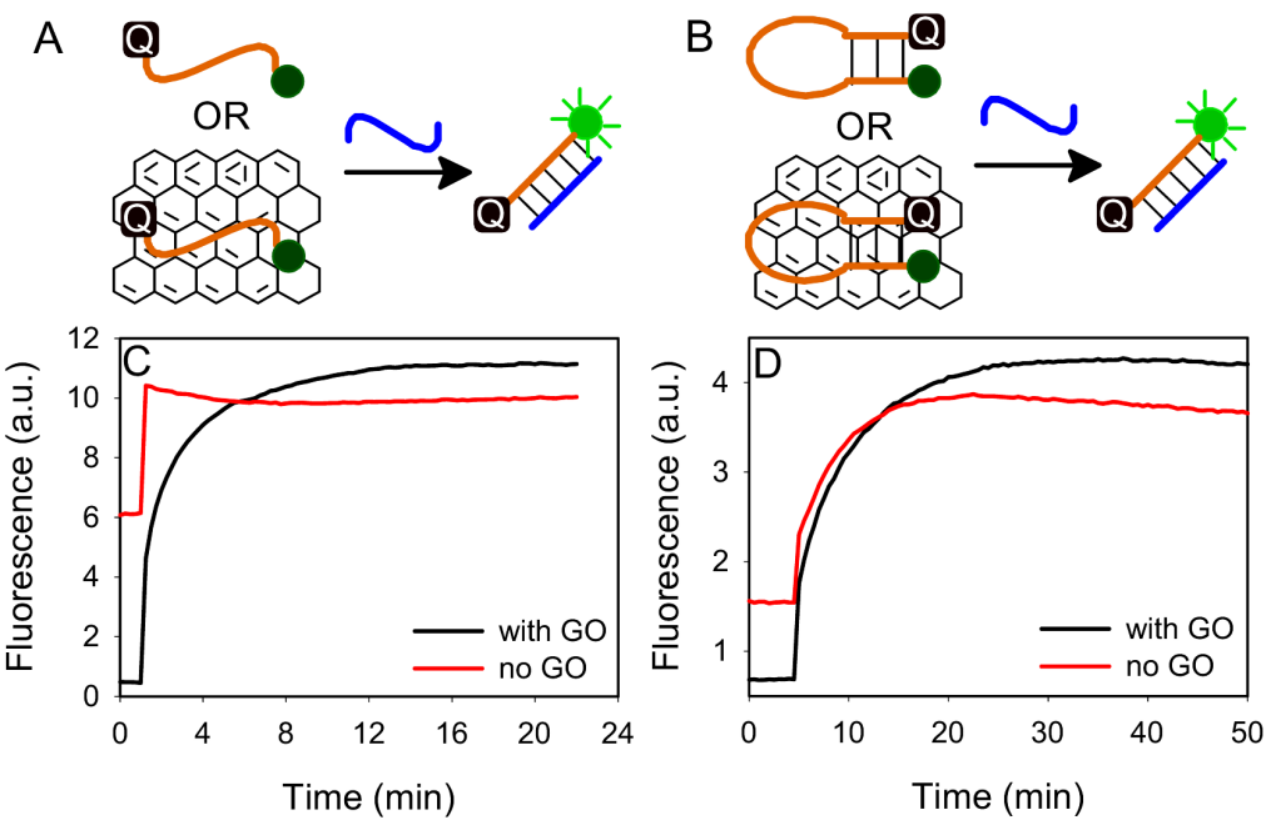

Figure 4. Schematic presentation of hybridization of non-structured DNA with cDNA (A) or hairpin DNA with cDNA (B) for the free DNA or DNA adsorbed on GO. (C) Hybridization kinetics for the reaction in (A). (D) Hybridization kinetics for the reaction in (B). 
Next we tested a molecular beacon with a hairpin structure to increase the hybridization activation energy barrier of the free DNA probe (Figure 4B). ${ }^{24-26}$ Adsorbing the molecular beacon probes on GO has been shown to suppress background and enhance selectivity, ${ }^{8 a, 27,28}$ while we used it here for the purpose of mechanistic study. Indeed, the free DNA hairpin hybridization kinetics was much slower (Figure 4D, red curve) compared to that for the non-structured DNA in Figure 4C. Adsorption of this hairpin to the GO surface resulted in a lower background and the kinetics of the reaction remains similar. The similar hybridization kinetics with and without GO for the hairpin DNA suggests that the displacement reaction should have a similar or slightly faster rate compared to hairpin hybridization to its cDNA in solution. Otherwise, the fluorescence signaling kinetics should be much slower in the presence of GO. The study of the hairpin probe further supports that GO is not a catalyst for DNA hybridization even when an artificial energy barrier is introduced, thus disproving the Langmuir-Hinshelwood mechanism from another perspective.

\section{Conclusions}

In conclusion, we have developed a set of experiments to probe the surface reaction mechanism of DNA on GO. The key experimental novelty here is to use probe DNA and its cDNA with a large adsorption energy difference on the GO surface. This can be readily achieved by tuning the nucleotide composition. Based on our results, the mechanism is probe DNA displacement followed by hybridization in solution, which has not been previously proposed for the GO/DNA system. At its current design, the efficiency of using the cDNA is quite low and even in the optimal design of using low affinity probe and high affinity cDNA, only $\sim 15 \%$ of the cDNA is used for signal generation. Therefore, there is a lot of room for rational engineering of the interface to improve sensitivity. Similar methods can also be applied to study reaction mechanism in other bio-nano systems. ${ }^{29}$ 


\section{ASSOCIATED CONTENT}

\section{Supporting Information}

DNA adsorption/desorption kinetics, additional melting curves, TEM. This material is available free of charge via the Internet at http://pubs.acs.org.

\section{AUTHOR INFORMATION}

$\S$ These authors contributed equally to this work.

\section{Corresponding Author}

Email: liujw@uwaterloo.ca

\section{ACKNOWLEDGMENT}

Funding for this work is from the University of Waterloo, the Canadian Foundation for Innovation, the NSERC of Canada and the Early Researcher Award from the Ontario Ministry of Research and Innovation.

\section{REFERENCES}

(1) (a) Geim, A. K.; Novoselov, K. S. Nat. Mater. 2007, 6, 183-191. (b) Rao, C. N. R.; Sood, A. K.; Subrahmanyam, K. S.; Govindaraj, A. Angew. Chem. Int. Ed. 2009, 48, 7752-7777. (c)Wang, Y.; Li, Z. H.; Wang, J.; Li, J. H.; Lin, Y. H. Trends Biotechnol. 2011, 29, 205-212. (d) Kim, J.; Cote, L. J.; Huang, J. Acc. Chem. Res. 2012, 45, 1356-1364. (e) Chen, D.; Feng, H.; Li, J. Chem. Rev. 2012, 112, 6027-6053. (f) Loh, K. P.; Bao, Q.; Eda, G.; Chhowalla, M. Nat Chem 2010, 2 , 1015-1024. (g) Wang, H.; Yang, R. H.; Yang, L.; Tan, W. H. ACS Nano 2009, 3, 2451-2460. (h) Guo, S. J.; Dong, S. J. Chem. Soc. Rev. 2011, 40, 2644-2672.

(2) (a) Lu, C. H.; Yang, H. H.; Zhu, C. L.; Chen, X.; Chen, G. N. Angew. Chem. Int. Ed. 2009, 48, 4785-4787. (b) He, S. J.; Song, B.; Li, D.; Zhu, C. F.; Qi, W. P.; Wen, Y. Q.; Wang, L. H.; Song, S. P.; Fang, H. P.; Fan, C. H. Adv. Funct. Mater. 2010, 20, 453-459. (c) Wu, M.;

Kempaiah, R.; Huang, P.-J. J.; Maheshwari, V.; Liu, J. Langmuir 2011, 27, 2731-2738. (d) Guo, Y.; Deng, L.; Li, J.; Guo, S.; Wang, E.; Dong, S. ACS Nano 2011, 5, 1282-1290. 
(3) Manohar, S.; Mantz, A. R.; Bancroft, K. E.; Hui, C.-Y.; Jagota, A.; Vezenov, D. V. Nano Lett. 2008, $8,4365-4372$.

(4) Varghese, N.; Mogera, U.; Govindaraj, A.; Das, A.; Maiti, P. K.; Sood, A. K.; Rao, C. N. R. ChemPhysChem 2009, 10, 206-210.

(5) Park, J. S.; Na, H.-K.; Min, D.-H.; Kim, D.-E. Analyst 2013, 138, 1745-1749.

(6) Huang, P.-J. J.; Liu, J. Anal. Chem. 2012.

(7) Tang, L.; Chang, H.; Liu, Y.; Li, J. Adv. Funct. Mater. 2012, 22, 3083-3088.

(8) (a) Li, F.; Huang, Y.; Yang, Q.; Zhong, Z. T.; Li, D.; Wang, L. H.; Song, S. P.; Fan, C. H. Nanoscale 2010, 2, 1021-1026. (b) Dong, H. F.; Gao, W. C.; Yan, F.; Ji, H. X.; Ju, H. X. Anal. Chem. 2010, 82, 5511-5517. (c) Guo, Y.; Deng, L.; Li, J.; Guo, S.; Wang, E.; Dong, S. ACS Nano 2011, 5, 1282-1290. (d) Wu, W.; Hu, H.; Li, F.; Wang, L.; Gao, J.; Lu, J.; Fan, C. Chem. Comm. 2011, 47, 1201-1203. (e) Song, Z.-L.; Zhao, X.-H.; Liu, W.-N.; Ding, D.; Bian, X.; Liang, H.; Zhang, X.-B.; Chen, Z.; Tan, W. Small 2012, 9, 951-957.

(9) Wen, Y. Q.; Xing, F. F.; He, S. J.; Song, S. P.; Wang, L. H.; Long, Y. T.; Li, D.; Fan, C. H. Chem. Comm. 2010, 46, 2596-2598.

(10) Song, Y. J.; Qu, K. G.; Zhao, C.; Ren, J. S.; Qu, X. G. Adv. Mater. 2010, 22, 2206-2210.

(11) Wang, Y.; Li, Z. H.; Hu, D. H.; Lin, C. T.; Li, J. H.; Lin, Y. H. J. Am. Chem. Soc. 2010, 132, 9274-9276.

(12) Lu, C.-H.; Li, J.; Lin, M.-H.; Wang, Y.-W.; Yang, H.-H.; Chen, X.; Chen, G.-N. Angew. Chem., Int. Ed. 2010, 49, 8454-8457.

(13) Tan, X.; Chen, T.; Xiong, X.; Mao, Y.; Zhu, G.; Yasun, E.; Li, C.; Zhu, Z.; Tan, W. Anal. Chem. 2012, 84, 8622-8627.

(14) Chang, H. X.; Tang, L. H.; Wang, Y.; Jiang, J. H.; Li, J. H. Anal. Chem. 2010, 82, 2341-2346.

(15) Wang, L.; Pu, K.-Y.; Li, J.; Qi, X.; Li, H.; Zhang, H.; Fan, C.; Liu, B. Adv. Mater. 2011, 23, 4386-4391. 
(16) Cheng, C.-L.; Zhao, G.-J. Nanoscale 2012, 4, 2301-2305.

(17) Akdim, B.; Pachter, R.; Day, P. N.; Kim, S. S.; Naik, R. R. Nanotechnology 2012, 23, 165703.

(18) Iliafar, S.; Wagner, K.; Manohar, S.; Jagota, A.; Vezenov, D. J. Phys. Chem. C 2012, 116, 13896-13903.

(19) Gowtham, S.; Scheicher, R. H.; Ahuja, R.; Pandey, R.; Karna, S. P. Phys. Rev. B 2007, 76, 033401.

(20) Gomez-Navarro, C.; Meyer, J. C.; Sundaram, R. S.; Chuvilin, A.; Kurasch, S.; Burghard, M.; Kern, K.; Kaiser, U. Nano Lett. 2010, 10, 1144-1148.

(21) Erickson, K.; Erni, R.; Lee, Z.; Alem, N.; Gannett, W.; Zettl, A. Adv. Mater. 2010, 22, 44674472.

(22) Lu, C. F.; Nadarajah, A.; Chittur, K. K. J. Colloid Interf. Sci. 1994, 168, 152-161.

(23) Hall, D. Anal. Biochem. 2001, 288, 109-125.

(24) Wang, K. M.; Tang, Z. W.; Yang, C. Y. J.; Kim, Y. M.; Fang, X. H.; Li, W.; Wu, Y. R.; Medley, C. D.; Cao, Z. H.; Li, J.; Colon, P.; Lin, H.; Tan, W. H. Angew. Chem. Int. Ed. 2009, $48,856-870$.

(25) Vallee-Belisle, A.; Ricci, F.; Plaxco, K. W. J. Am. Chem. Soc. 2012, 134, 2876-2879.

(26) Ricci, F.; Vallee-Belisle, A.; Porchetta, A.; Plaxco, K. W. J. Am. Chem. Soc. 2012, 134, $15177-$ 15180.

(27) Lu, C. H.; Li, J.; Liu, J. J.; Yang, H. H.; Chen, X.; Chen, G. N. Chem. Eur. J. 2010, 16, 48894894.

(28) Zhou, J.; Lu, Q.; Tong, Y.; Wei, W.; Liu, S. Talanta 2012, 99, 625-630.

(29) (a) Yang, R. H.; Jin, J. Y.; Chen, Y.; Shao, N.; Kang, H. Z.; Xiao, Z.; Tang, Z. W.; Wu, Y. R.; Zhu, Z.; Tan, W. H. J. Am. Chem. Soc. 2008, 130, 8351-8358. (b) Zhu, C.; Zeng, Z.; Li, H.; Li, F.; Fan, C.; Zhang, H. J. Am. Chem. Soc. 2013, 135, 5998-6001. (c) Opdahl, A.; Petrovykh, D. Y.; Kimura-Suda, H.; Tarlov, M. J.; Whitman, L. J. Proc. Natl. Acad. Sci. U.S.A. 2007, 104, 9- 
14. (d) Schreiner, S. M.; Shudy, D. F.; Hatch, A. L.; Opdahl, A.; Whitman, L. J.; Petrovykh, D. Y. Anal. Chem. 2010, 82, 2803-2810. (e) Li, H.; Zhang, Y.; Wang, L.; Tian, J.; Sun, X. Chem. Comm. 2011, 47, 961-963. (f) Li, H.; Zhang, Y.; Luo, Y.; Sun, X. Small 2011, 7, 1562-1568. (g) Zhai, J.; Li, H.; Sun, X. RSC Advances 2011, 1, 36-39. (h) Yang, R. H.; Tang, Z. W.; Yan, J. L.; Kang, H. Z.; Kim, Y. M.; Zhu, Z.; Tan, W. H. Anal. Chem. 2008, 80, 7408-7413. 